\title{
Is Helping Really Helping? Health-Related Quality of Life after TBI Predicting Caregiver Depression Symptom Trajectories in Latin America
}

\author{
Chimdindu Ohayagha ${ }^{1}$, Paul B. Perrin ${ }^{1}\left(\mathbb{D}\right.$, Annahir N. Cariello ${ }^{1}$ and Juan Carlos Arango-Lasprilla ${ }^{2,3,4, *(D)}$ \\ 1 Department of Psychology, Virginia Commonwealth University, Richmond, VA 23284, USA; \\ ohayaghac@mymail.vcu.edu (C.O.); pperrin@vcu.edu (P.B.P.); carielloa@mymail.vcu.edu (A.N.C.) \\ 2 BioCruces Bizkaia Health Research Institute, 40903 Barakaldo, Spain \\ 3 IKERBASQUE, Basque Foundation for Science, 48009 Bilbao, Spain \\ 4 Department of Cell Biology and Histology, University of the Basque Country (UPV/EHU), 48940 Leioa, Spain \\ * Correspondence: jcalasprilla@gmail.com
}

check for updates

Citation: Ohayagha, C.; Perrin, P.B.; Cariello, A.N.; Arango-Lasprilla, J.C. Is Helping Really Helping? HealthRelated Quality of Life after TBI Predicting Caregiver Depression Symptom Trajectories in Latin America. Int. J. Environ. Res. Public Health 2021, 18, 1247. https:// doi.org/10.3390/ijerph18031247

Received: 21 December 2020

Accepted: 21 January 2021

Published: 30 January 2021

Publisher's Note: MDPI stays neutral with regard to jurisdictional claims in published maps and institutional affiliations.

Copyright: (c) 2021 by the authors. Licensee MDPI, Basel, Switzerland. This article is an open access article distributed under the terms and conditions of the Creative Commons Attribution (CC BY) license (https:// creativecommons.org/licenses/by/ $4.0 /)$.

\begin{abstract}
Previous research connecting health-related quality of life (HRQoL) in people with traumatic brain injury (TBI) and caregiver mental health has primarily been conducted cross-sectionally in the U.S. and Western Europe. This study, therefore, examined how HRQoL in individuals immediately after their TBI predicts longitudinal caregiver depression symptom trajectories in Latin America. A sample of 109 patients with an acute TBI and 109 caregivers (total $n=218$ ) was recruited from three hospitals in Mexico City, Mexico, and in Cali and Neiva, Colombia. TBI patients reported their HRQoL while they were still in hospital, and caregivers reported their depression symptoms at the same time and at 2 and 4 months later. Hierarchal linear models (HLM) found that caregiver depression symptom scores decreased over time, and lower patient mental health and pain-related quality of life at baseline (higher pain) predicted higher overall caregiver depression symptom trajectories across the three time points. These findings suggest that in Latin America, there is an identifiable relationship between psychological and pain-related symptoms after TBI and caregiver depression symptom outcomes. The results highlight the importance of early detection of caregiver mental health needs based in part upon patient HRQoL and a culturally informed approach to rehabilitation services for Latin American TBI caregivers.
\end{abstract}

Keywords: traumatic brain injury; caregivers; Latin America; depression; health-related quality of life

\section{Introduction}

\subsection{Traumatic Brain Injury in the U.S. and Latin American Countries}

Traumatic brain injury (TBI) is one of the major contributors to death and disability around the world [1]. TBI is defined as an alteration to brain functioning as a result of externally applied forces [2]. The extent to which the pattern of damage is assessed is informed by the external mechanical force, its nature, direction, intensity, and duration [3]. Secondary damage, or delayed non-mechanical damage, typically involves pathological processes initiated after the impact that can result in delayed clinical presentations [4]. Secondary damage to the brain often includes cerebral ischemia, intracranial hypertension, increased intracranial pressure, hypoxia, oxidative stress, ecotoxicity, and apoptosis [5]. Common complications include neurological atrophy, neuroendocrine abnormalities, sensory disorders, fatigue, insomnia, and posttraumatic seizure disorders [6,7]. TBI can be a life-altering experience, with an estimated annual occurrence in the U.S. of 1.4 million people [8], or 500-800 new cases per 100,000 people each year [9]. Falls, motor vehicle accidents, assaults, and sports-related accidents are common causes of TBI [8], and many TBI survivors often face long-term disability [10]. Lower- and middle-income countries (LMICs) such as many Latin American countries have the highest incidence of intracranial injury worldwide [11]. 
Contrary to the U.S., the primary mechanisms of injury in LMICs are road traffic injuries and violence [11,12]. Recent estimates suggest that there are approximately 909 new cases of TBI per 100,000 people in LMICs each year [9]. In Mexico, TBI is ranked as the third leading cause of death, often resulting from motor vehicle accidents [13]. In Colombia, hostile guerillas and landmine explosions are also major contributors to TBI [14] with a TBI prevalence rate of approximately 6.4 per 1000 people [15].

Although TBI is a major contributor to death and disability in the U.S., according to the World Health Organization, more than $90 \%$ of deaths caused by a TBI occur in LMICs [16], where $85 \%$ of the world population lives [17]. Elevated rates of TBI are often due to living below the poverty line, residing in a conflict zone [16], a lack of preventative measures, and having less developed health systems to address physical and mental health outcomes [12,18]. Cultural and economic inequities are also significant contributors to TBI [19]. Despite the high rates of death after TBI in Latin America, there is a dearth of research in the literature or data addressing the burden of TBI in Latin America, which could limit the implementation of comprehensive TBI prevention and rehabilitation programs in the region [12].

\subsection{Functional Outcomes Following TBI}

People with TBI experience physical, behavioral, emotional, and cognitive difficulties that can persist many years after injury $[20,21]$ and affect many aspects of everyday living, including independence, mobility, employment, and community integration [22]. Social and interpersonal skills are among the most notable impairments and have been shown to interfere with community living, occupational status, and sustainment of interpersonal relationships $[23,24]$.

\subsection{Health-Related Quality of Life Following TBI}

Return to productive activity is a primary rehabilitation goal for many individuals with TBI, although complete restoration to pre-injury functioning seldomly occurs, often leaving individuals with TBI with reductions in perceived quality of life $[25,26]$. Healthrelated quality-of-life (HRQoL) is a global index of overall quality of life and is defined as an individual's satisfaction with the physical, psychological, and social provinces of life grounded in one's self-concept and self-efficacy, in addition to other aspects traditionally not categorized as health, such as quality of the environment, independence, and social support [27-29]. The evaluation of HRQoL is primarily captured through the self-report of an individual with TBI.

Several studies have shown that individuals with TBI report lower HRQoL than the general population [29-31]. Arango-Lasprilla and colleagues [32] investigated HRQoL in individuals with TBI living in Colombia and found that after adjusting for depression, socioeconomic status, social support, and cognitive performance, those with TBI scored poorer than healthy controls on a variety of HRQoL domains such as emotional functioning, physical functioning, and pain. These reductions often impact relationships with family members and caregivers, resulting in increased burden in caregivers [33,34].

\subsection{Caregiver Mental Health Following Traumatic Brain Injury}

People with TBI often require supervision and support from caregivers [34]. Caregiving can have positive effects on a caregiver's well-being, such as developing a sense of strength when confronting adverse circumstances, providing a sense of accomplishment, and increasing emotional intimacy with the care recipient [35]. However, the physical, emotional, and cognitive demands of caregiving can surpass caregivers' capacity to adequately adjust to the novel role of caregiving [34,36]. Caregivers have been shown to experience increased depression [37-40]. Arango-Lasprilla and colleagues [41] found that TBI caregivers in Colombia reported emotional support as one of the most salient unmet needs, and unmet needs have been shown to be closely related to TBI caregiver mental health problems in Mexico [42]. Similarly, Stevens and colleagues [43] found that Colombian 
caregivers reported being overwhelmed by caretaking responsibilities. Compared to noncaregivers, caregivers have an increased risk for depression and overall poor health $[37,38]$, and within LMICs like those in Latin America, caregiver mental health issues could be more widespread.

\subsection{Current Study}

Some studies have shown that patient HRQoL after TBI impacts caregiver depression $[44,45]$, while others have identified cognitive, behavioral, and emotional changes as strong predictors of caregiver depression [46]. TBI is a family experience, impacting all members of the family. Within Latin American cultures, the familial unit is central to many aspects of life, and with the responsibility of caregiving placed upon family members, caregivers are often unprepared and lack the experience and knowledge necessary to provide comprehensive, ongoing care [47]. The mental health of TBI caregivers is paramount in terms of potentially affecting the quality of informal care provided to people with TBI. The TBI literature has shown that caregiver depression can be influenced by a myriad of factors. Harris and colleagues [34] reported that caregivers' appraisal of adverse family effects mediated the relationship between stressors and depression, while social support moderated the relationship between adverse family effects and depression; $46 \%$ of the variance in caregiver depression was accounted for by caregivers' appraisal of adverse family effects and social support. Linn and Willer [48] examined brain-injured patients and their spousal caregivers and found that depression was the predominant outcome, with $73 \%$ of spousal caregivers and $70 \%$ of patients exceeding the scale cutoff for depressive symptoms; the study also indicated that female spouses reported higher levels of depression compared to male spouses. Despite these findings, few studies have examined the connections between TBI patient HRQoL and caregiver depression symptoms, especially within LMICs like many in Latin America. As a result, this study aimed to examine which patient HRQoL domains predict caregiver depression symptoms over the first 4 months after injury in two countries and three hospitals in Latin America.

\section{Method}

\subsection{Participants}

A sample of 109 patients with a new TBI and their caregivers (total $n=218$ ) was recruited from three hospitals in Mexico City, Mexico, and in Cali and Neiva, Colombia. Individuals with TBI met the following inclusion criteria: (a) have a physician-confirmed diagnosis of moderate or severe TBI (Glasgow Coma Scale $<13$ ) in their medical record, (b) be at least age 18, (c) be able to communicate in Spanish, (d) be a previous or current patient at the referring center, and (e) be willing to participate with their caregiver. Caregivers met the following inclusion criteria: (a) must be the primary caregiver providing care for the person with TBI, (b) be related to the person with TBI directly via blood or marriage and/or be a close friend, (c) live in the household with the individual with TBI, and (d) be able to communicate in Spanish. Caregivers must also have had no previously documented history of severe psychological or neurological problems. Participant demographics appear in Table 1. 
Table 1. Sample means, SDs, and percentages of demographic variables.

\begin{tabular}{|c|c|c|}
\hline Caregiver Demographics & & $(n=109)$ \\
\hline Age, $M(S D)$ & & $41.46(13.85)$ \\
\hline Education, years, $M(S D)$ & & $10.22(5.00)$ \\
\hline \multirow{2}{*}{ Sex, $n(\%)$} & Male & $20(18.3)$ \\
\hline & Female & $89(81.7)$ \\
\hline \multirow[t]{5}{*}{ Relationship to patient, $n(\%)$} & Parent & $11(10.1)$ \\
\hline & Sibling & $5(4.6)$ \\
\hline & Child & $1(0.9)$ \\
\hline & Aunt/Uncle & $1(0.9)$ \\
\hline & Other & $41(37.6)$ \\
\hline \multirow[t]{6}{*}{ Pre-injury Employment Status, $n(\%)$} & Employed Full-time & $28(25.7)$ \\
\hline & Employed Part-time & $22(20.2)$ \\
\hline & Home/Family care & $34(31.2)$ \\
\hline & Unemployed & $18(16.5)$ \\
\hline & Student & $5(4.6)$ \\
\hline & Retired/Pension & $2(1.8)$ \\
\hline Patient Demographics & & $(n=109)$ \\
\hline Age, $M(S D)$ & & $35.87(14.08)$ \\
\hline Days in the hospital, $M(S D)$ & & $20.78(28.95)$ \\
\hline \multirow[t]{2}{*}{ Sex, $n(\%)$} & Male & $90(82.6)$ \\
\hline & Female & $19(17.4)$ \\
\hline \multirow[t]{9}{*}{ Cause of Injury, $n(\%)$} & Automobile Accident & $12(11.0)$ \\
\hline & Motor Accident & $41(37.6)$ \\
\hline & Bicycle Accident & $3(2.8)$ \\
\hline & Pedestrian Accident & $7(6.4)$ \\
\hline & Firearm & $2(1.8)$ \\
\hline & Act of Violence & $17(15.6)$ \\
\hline & Sports Accident & $1(0.9)$ \\
\hline & Fall & $23(21.1)$ \\
\hline & Other & $3(2.8)$ \\
\hline \multirow[t]{6}{*}{ Pre-injury Employment Status, $n(\%)$} & Employed Full-time & $34(31.2)$ \\
\hline & Employed Part-time & $9(8.3)$ \\
\hline & Home/Family Care & $8(7.3)$ \\
\hline & Unemployed & $49(45)$ \\
\hline & Student & $7(6.4)$ \\
\hline & Retired/Pension & $2(1.8)$ \\
\hline
\end{tabular}

\subsection{Measures}

\subsubsection{Short Form Health Survey}

The Spanish version of the Medical Outcomes Study Short-Form Health Survey (SF-36) was utilized to measure HRQoL. The SF-36 is a well-validated instrument for measuring health status and outcomes from the patient's perspective and has been widely used among people with TBI $[49,50]$. The SF-36 consists of 36 items that yield a profile of eight multi-item subscales that assess the following dimensions of health: (1) physical function, (2) physical role, (3) bodily pain, (4) general health, (5) energy/vitality, (6) social function, (7) emotional role, and (8) mental health. The eight subscales fall under two overarching categories: physical health and mental health. Scores range from 0 to 100, with higher scores reflecting greater HRQoL. The Spanish version of the SF-36 has well-established reliability and validity $[32,51]$.

\subsubsection{Patient Health Questionnaire-9}

The Patient Health Questionnaire-9 (PHQ-9) depression scale is a well-validated, Diagnostic and Statistical Manual of Mental Disorders-Fourth Edition (DSM-IV) criterionbased measure for assessing depression symptoms, severity of symptoms, and monitoring treatment response [52]. The PHQ-9 maintains comparable sensitivity and specificity without the need for a two-step questionnaire to assess diagnostic criteria for depressive 
symptomatology, yet contains significantly fewer items among other depression symptom scales [53]. The PHQ-9 consists of 9 items and can be entirely completed by the patient, as it directs the respondent to indicate how often he/she has been bothered by each item using a response from 0 (not at all) to 3 (nearly every day). Total score ranges from 0 to 27, with higher scores indicating higher depression symptom severity. The Spanish version of the PHQ-9 has well-established reliability and validity in assessing depression symptoms within Spanish-speaking populations [54,55].

\subsection{Procedure}

Informed consent, questionnaires, and all other study materials were approved by the Virginia Commonwealth University Institutional Review Board, in addition to approval from the ethics committees at each site in Latin America. A detailed review of the patient's records was conducted to assess if the patient (and later the caregiver) met preliminary eligibility and full inclusion/exclusion criteria. All data collections were conducted by psychologists or highly trained research assistants, either at the primary sites or in-home, depending upon the needs and preferences of the participants.

\section{Results}

\subsection{Preliminary Analyses}

A correlation matrix among the primary study variables is presented for reference in Table 2. In terms of the longitudinal analyses, one participant dropped out of the study at 2 months and four participants at 4 months. Full information maximum likelihood (FIML) estimation was used to account for missing data. Two separate main effects hierarchical linear models (HLMs) were used to examine baseline patient physical and mental HRQoL predictors of caregiver depression symptom trajectories across baseline, 2 months, and 4 months. Unconditional growth linear (straight line) and quadratic ( $U$-shaped) models were run first with no predictors to determine the most accurate model for linear or polynomial curvature of caregiver depression symptom scores over time. The $-2 \log$ likelihood (-2LL) of the unconditional growth model with linear time was 1778.96, whereas the -2LL of the unconditional growth model with the addition of quadratic time was 1775.96, which represented a drop of 3.01 that did not surpass the critical $\chi^{2}$ value of 3.84 for statistical significance $(p<0.05)$. As a result, the movement of caregiver depression symptom trajectories overtime was best modeled as linear.

Table 2. Correlation matrix.

\begin{tabular}{|c|c|c|c|c|c|c|c|c|c|c|}
\hline Variable & 1 & 2 & 3 & 4 & 5 & 6 & 7 & 8 & 9 & 10 \\
\hline 1. Caregiver Depression Sx. BL & & & & & & & & & & \\
\hline 2. Caregiver Depression Sx. 2M & $0.680 * *$ & & & & & & & & & \\
\hline 3. Caregiver Depression Sx. 4M & $0.690 * *$ & $0.891 * *$ & & & & & & & & \\
\hline 4. Physical Functioning & -0.150 & -0.170 & $-0.194 *$ & & & & & & & \\
\hline 5. Role-Physical & -0.054 & 0.063 & 0.023 & $0.447^{* *}$ & & & & & & \\
\hline 6. Role-Emotional & $-0.232 *$ & -0.142 & -0.121 & $0.250 * *$ & $0.514 * *$ & & & & & \\
\hline 7. Vitality & $-0.193 *$ & -0.168 & $-0.213^{*}$ & $0.490 * *$ & $0.419 * *$ & $0.396^{* *}$ & & & & \\
\hline 8. Mental Health & $-0.338 * *$ & $-0.276^{* *}$ & $-0.295 * *$ & $0.406^{* *}$ & $0.316^{* *}$ & $0.404 * *$ & $0.709 * *$ & & & \\
\hline 9. Social Functioning & $-0.234 *$ & -0.189 & -0.187 & $0.496 * *$ & $0.381 * *$ & $0.464^{* *}$ & $0.560 * *$ & $0.506 * *$ & & \\
\hline 10. Pain & $-0.266^{* *}$ & -0.166 & -0.143 & $0.506^{* *}$ & $0.388^{* *}$ & $0.310^{* *}$ & $0.478^{* *}$ & $0.375^{* *}$ & $0.485^{* *}$ & \\
\hline 11. General Health & -0.128 & -0.184 & -0.174 & $0.428 * *$ & 0.286 ** & $0.388^{* *}$ & $0.529 * *$ & 0.551 ** & $0.444^{* *}$ & 0.149 \\
\hline
\end{tabular}

Note. ${ }^{*}=p<0.05 ;{ }^{* *}=p<0.01 ;$ Sx. $=$ symptoms. $\mathrm{BL}=$ baseline.

\subsection{Main Analyses}

In the first main effects HLM predicting caregiver depression symptom trajectories, time and the four indices of patient physical HRQoL at baseline were entered simultaneously as fixed effects after being centered. All statistically significant and non-significant fixed effects from the HLM and their b-weights, $p$-values, standard errors (SEs), and 95\% confidence intervals appear in Table 3 . Time and pain yielded statistically significant effects. Caregiver depression symptom scores decreased over time. Higher patient pain-related quality of life at baseline (lower pain) was associated with lower caregiver depression 
across the three time points (Figure 1). A follow-up HLM was run with time, pain-related

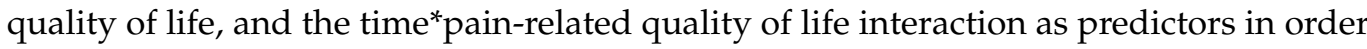
to determine whether caregiver depression symptom trajectories changed differentially over time as a function of patient pain-related quality of life (Table 3). The interaction term was significant, suggesting that caregiver depression symptom scores started higher but decreased more rapidly if patients had low baseline pain-related quality of life.

Table 3. Predictors of caregiver depression symptom trajectories at baseline, 2 months, and 4 months based on TBI HRQoL.

\begin{tabular}{|c|c|c|c|c|c|}
\hline \multirow[t]{2}{*}{ Predictor } & \multirow[t]{2}{*}{$b$-Weight } & \multirow[t]{2}{*}{$S E$} & \multirow[t]{2}{*}{$p$-Value } & \multicolumn{2}{|c|}{ 95\% Confidence Interva } \\
\hline & & & & Lower & Upper \\
\hline \multicolumn{6}{|l|}{ Main Effects Model 1} \\
\hline Intercept & 5.67 & 0.46 & 0.000 & 4.75 & 6.58 \\
\hline Time & -0.64 & 0.18 & 0.001 & -1.00 & -0.28 \\
\hline Physical Functioning & -0.01 & 0.02 & 0.510 & -0.04 & 0.02 \\
\hline Role-Physical & 0.02 & 0.01 & 0.094 & -0.00 & 0.05 \\
\hline Pain & -0.03 & 0.02 & 0.041 & -0.06 & -0.00 \\
\hline General Health & -0.03 & 0.02 & 0.142 & -0.07 & 0.01 \\
\hline \multicolumn{6}{|c|}{ Interaction Effects Model 1} \\
\hline Intercept & 5.62 & 0.47 & 0.000 & 40.69 & 6.55 \\
\hline Time & -0.64 & 0.18 & 0.000 & -1.00 & -0.29 \\
\hline Pain & -0.04 & 0.01 & 0.003 & -0.07 & -0.01 \\
\hline Time*Pain & 0.01 & 0.01 & 0.020 & 0.002 & 0.02 \\
\hline \multicolumn{6}{|l|}{ Main Effects Model 2} \\
\hline Intercept & 5.64 & 0.46 & 0.000 & 4.73 & 6.55 \\
\hline Time & -0.70 & 0.18 & 0.000 & -1.05 & -0.34 \\
\hline Role-Emotional & -0.01 & 0.01 & 0.603 & -0.03 & 0.02 \\
\hline Vitality & 0.02 & 0.03 & 0.439 & -0.03 & 0.07 \\
\hline Mental Health & -0.07 & 0.03 & 0.014 & -0.12 & -0.01 \\
\hline Social Functioning & -0.01 & 0.02 & 0.560 & -0.04 & 0.02 \\
\hline \multicolumn{6}{|c|}{ Interaction Effects Model 2} \\
\hline Intercept & 5.62 & 0.46 & 0.000 & 4.71 & 6.52 \\
\hline Time & -0.64 & 0.18 & 0.000 & -1.00 & -0.29 \\
\hline Mental Health & -0.07 & 0.02 & 0.000 & -0.11 & -0.04 \\
\hline Time*Mental Health & 0.01 & 0.01 & 0.168 & -0.00 & 0.02 \\
\hline
\end{tabular}

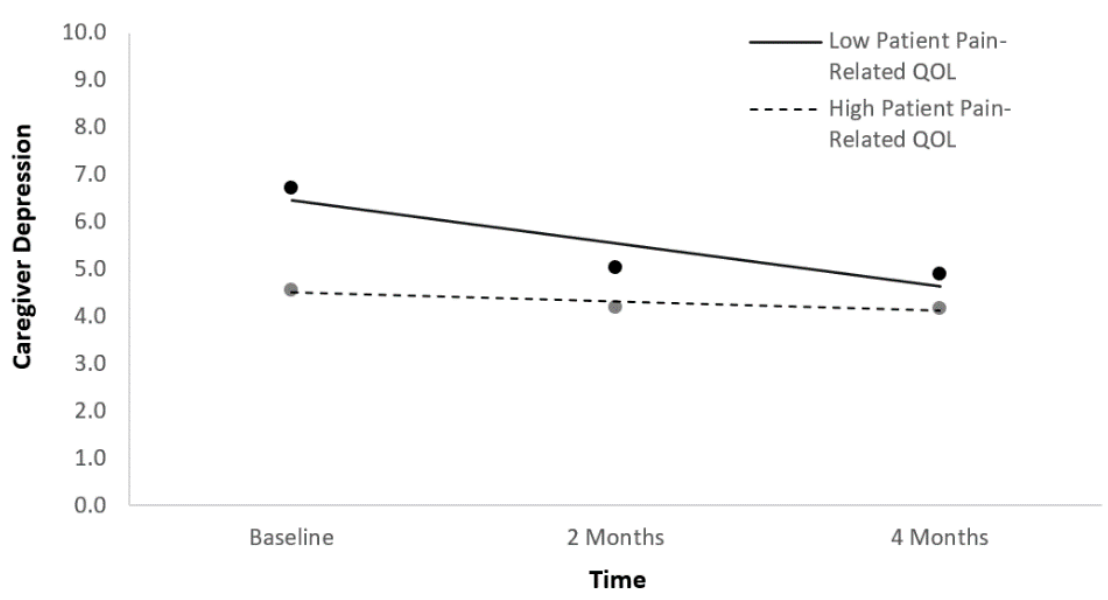

Figure 1. Caregiver depression symptom trajectories as a function of patient pain-related quality of life.

In the second main effects HLM predicting caregiver depression symptom trajectories, time and the four indices of patient mental HRQoL at baseline were entered simultaneously as fixed effects after being centered. In the HLM, time and mental health yielded statistically 
significant effects such that better patient mental health at baseline was associated with lower caregiver depression symptoms across the three time points (Table 3; Figure 2). A follow-up HLM was run with time, patient mental health, and the time*mental health interaction as predictors in order to determine whether caregiver depression symptom trajectories changed differentially over time as a function of patient mental health (Table 3). The interaction term was not significant in this model, suggesting there was no differential change.

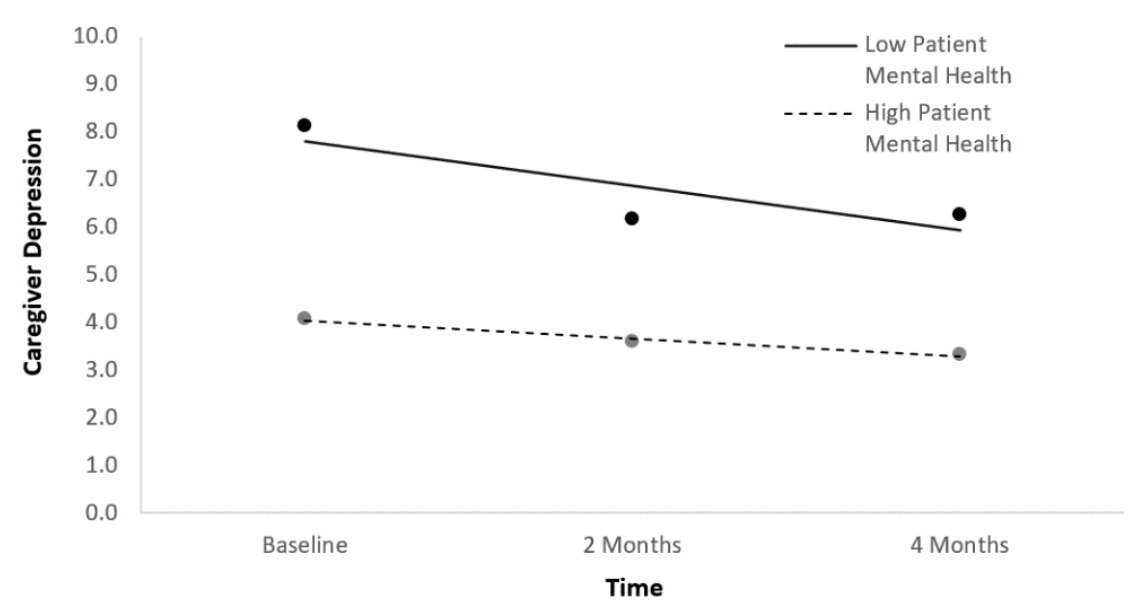

Figure 2. Caregiver depression symptom trajectories as a function of patient mental health.

\section{Discussion}

This study is the first to examine how HRQoL in individuals immediately after their TBI predicts longitudinal caregiver depression symptom trajectories in Latin America. Results suggested that caregiver depression symptom scores decreased over time, and lower patient mental health and pain-related quality of life at baseline (higher pain) predicted higher overall caregiver depression symptom trajectories across the three time points. There was no differential change over time in caregiver depression symptom trajectories as a function of patient mental health, though there was as a function of pain.

Despite the improvement in caregiver depression symptoms over time, previous cross-sectional research in Mexico has found that relative to healthy age-matched controls, TBI caregivers who had been providing care for a minimum of 3 months had substantially worse satisfaction with life, self-esteem, depression, and anxiety [56], as well as lower mental HRQoL [20]. As a result, the improvement in depression symptom scores over time found in the current study is unlikely to reach levels seen in healthy controls, but nonetheless, it suggests positive psychological adjustment to their new caregiving role.

The current study's finding that lower pain-related quality of life (higher pain) in patients after TBI predicts higher caregiver depression symptom trajectories is unique in the literature in that the current study is the first to link pain with caregiver depression symptoms over time in Latin American countries. Given the cultural influences on TBI rehabilitation, the study also highlights TBI impairments that transcend cultures. Research suggests that 22-95\% of adults with TBI experience chronic pain after injury [57-59]. Sullivan-Sign et al. [60] found that patient pain was the most prevalent $(70 \%)$ at baseline and was significantly associated cross-sectionally with patients' own depression. Lahz and Bryant [61] found that chronic pain occurred in 58\% of mild TBI and $52 \%$ of moderate/severe TBI patients; headaches were the most commonly reported pain problem. A literature review examining the prevalence of chronic pain after TBI identified twelve studies that suggested an overall prevalence rate of $57.8 \%$ for chronic headaches in civilian and military samples [62]. A possible interpretation of these findings could be that patient pain creates a lot of psychological distress for patients which then transfers over to psychological distress for caregivers.

Directly in line with this interpretation is the current finding that lower patient mental health at baseline predicted higher caregiver depression symptom trajectories. This finding 
has generally been supported by previous cross-sectional research. For example, Perrin and colleagues [63] found that brain injury patient depression was closely tied to caregiver psychosocial dysfunction in a large international sample. Stevens and colleagues [43] reported that among Spanish-speaking caregivers, caregivers' perception of patient functioning and depression was the single best predictor of both caregiver burden and depression. Relatedly, Kreutzer and colleagues [64] found that caregivers' perceptions of patient neurobehavioral problems were tied to caregivers' self-report of depression; indeed, in the current study, neurobehavioral issues in patients could have been producing patient mental health problems, which then drove higher caregiver depression symptom trajectories.

\subsection{Clinical Implications}

Clinical assessment of patient pain and mental health while the individual with TBI is still in the hospital may inform best practices regarding treatment modalities. The larger literature has shown that pain and mental health are common co-occurring conditions [60]. It is imperative that rehabilitation clinicians evaluate potential comorbidity of pain and mental health; if patient pain is a primary variable that results in decreased mental health, then subsequent treatment for pain may lead to improvements of both mental health and pain, including caregiver mental health. Multidisciplinary interventions have been shown be most effective for pain management $[65,66]$. Numerous studies have confirmed that in addition to medication management, interventions such as cognitive-behavioral therapy, biofeedback, and relaxation are effective in managing pain [67]. However, the absence of psychological and mental health services may hinder patients' ability to adhere to a treatment program effectively [68] which not only affects the patient but also the caregiver.

An integrative and culturally informed patient-caregiver approach to TBI rehabilitation would be optimal in Latin America for addressing physical consequences, such as chronic pain, and the mental health needs of both the patient and caregiver. Contrary to the fact that Latinx cultures and value systems center on collectivism and familism, TBI rehabilitation in Latin America often focuses exclusively on the individual with TBI and rarely includes interventions for caregivers [20]. Utilizing a culturally informed approach focused on the integration of caregivers during all stages of treatment is imperative given that previous studies have shown that Latin American caregivers report emotional support as a salient unmet need [41].

A combined patient-caregiver approach may also further strengthen cultural and familial values and lead to better rehabilitation outcomes. Familism, or familismo, refers to Latinos' identity as part of a family [69]; it postulates that the needs of all members of a group bear greater importance than the individual's needs, and therefore the individual sacrifices for the good of the group [70]. McCubbin and McCubbin [71] reported that families that emphasize optimism, collectivism, and their family unit, as well as shared values and goals, were more likely to positively adapt to TBI. Lehan et al. [72] found that TBI patients and caregivers who reported greater levels of family adaptability also endorsed better family communication and greater family satisfaction.

Caregiver intervention programs that are empirically supported often include stress management techniques centered on post-injury adjustment [73], psychoeducation [74], behavioral management techniques [75], and problem-solving training for family caregivers [76]. These interventions have been shown to reduce caregiver burden, anxiety, and depression [73,74,76]. Kreutzer et al. [45] investigated the benefits of a family intervention for family members of TBI patients and found that family members showed a greater number of met needs and perceived fewer obstacles to access services following intervention. When implementing these techniques to Latin America, special consideration should be given to ensure that techniques are culturally appropriate for the population, as the majority of current interventions and techniques were created for English-speaking or Western populations. 


\subsection{Limitations and Future Directions}

Although this study is among the first to examine the association between patient HRQoL and caregiver depression symptoms in Latin American TBI caregivers and patients, several notable limitations should be taken into account when interpreting the results. First, the study was conducted in two Latin American countries, and therefore, the results are not generalizable to all countries in Latin America. Latin American countries and individuals are extremely diverse, particularly with regard to socioeconomic status and rural vs. urban location. Future studies should examine whether the findings hold in other Latin American countries and regions different from those sampled in the current study. Second, although advanced trajectory modeling was utilized, study results were correlational and the analyses cannot infer causality within these relationships. Future studies should consider the use of a cross-lagged panel design to further investigate causality between patient HRQoL and caregiver depression symptoms. Third, because all measures in this study were self-report, participants likely experienced less severe TBI-related impairments compared to others with more severe impairments who, therefore, were unable to consent and participate. Caregivers of severely impaired patients may have experienced greater depression symptoms and thus may be underrepresented in the sample. Future studies should consider the combination of both self-report and objective measures of functioning. Fourth, the sample of TBI patients was overrepresented with male patients and female caregivers; caution should be taken in the generalizability of results to female patients with TBI or male caregivers. Fifth, the study consisted of a sample of relatively moderate size; future studies should recruit a larger sample from a greater number of Latin American countries. Lastly, the study only examined caregiver depression symptom trajectories at baseline, 2 months, and 4 months post-discharge. Subsequent studies should examine Latin American patient and caregiver relationships at longer time intervals, such as at 6 months, 1 year, or 5 years.

\section{Conclusions}

The current study investigated the associations among TBI patient HRQoL and caregiver depression symptoms in three sites and two countries in Latin America. The study showed that caregiver depression symptom scores decreased over time, and lower patient mental health and pain-related quality of life at baseline (higher pain) predicted higher overall caregiver depression symptom trajectories across the three time points. Because caregivers' mental health influences the quality of informal care they can provide and is also connected to patient pain and mental health, evidence-based and culturally appropriate interventions must address the rehabilitation and mental health needs of both patients and familial caregivers.

Author Contributions: Conceptualization, P.B.P., J.C.A.-L., and C.O.; methodology, P.B.P., J.C.A.-L.; formal analysis, A.N.C., C.O., and P.B.P.; Writing-Original draft preparation, C.O., A.N.C.; WritingReview and editing, P.B.P. and J.C.A.-L.; supervision, P.B.P. and J.C.A.-L.; project administration, P.B.P. and J.C.A.-L.; funding acquisition P.B.P. and J.C.A.-L. All authors have read and agreed to the published version of the manuscript.

Funding: This study was funded by grant \#R21TW009746 from Fogarty International Center of the National Institutes of Health.

Institutional Review Board Statement: The study was conducted according to the guidelines of the Declaration of Helsinki, and approved by the Institutional Review Board of Virginia Commonwealth University Institutional Review Board.

Informed Consent Statement: Informed consent was obtained from all subjects involved in the study.

Data Availability Statement: The data presented in this study are available on request from the corresponding author. The data are not publicly available due to participant confidentiality.

Conflicts of Interest: The authors declare no conflict of interest. 


\section{References}

1. De Silva, M.J.; Roberts, I.; Perel, P.; Edwards, P.; Kenward, M.G.; Fernandes, J.; Shakur, H.; Patel, V. CRASH Trial Collaborators. Patient Outcome after Traumatic Brain Injury in High-, Middle- and Low-Income Countries: Analysis of Data on 8927 Patients in 46 Countries. Int. J. Epidemiol. 2009, 38, 452-458. [CrossRef]

2. Menon, D.K.; Schwab, K.; Wright, D.W.; Maas, A.I. Demographics and Clinical Assessment Working Group of the International and Interagency Initiative toward Common Data Elements for Research on Traumatic Brain Injury and Psychological Health. Position Statement: Definition of Traumatic Brain Injury. Arch. Phys. Med. Rehabil. 2010, 91, 1637-1640. [CrossRef]

3. McCrory, P.; Johnston, K.; Meeuwisse, W.; Aubry, M.; Cantu, R.; Dvorak, J.; Graf-Baumann, T.; Kelly, J.; Lovell, M.; Schamasch, P. Summary and Agreement Statement of the 2nd International Conference on Concussion in Sport, Prague 2004. Br. J. Sports Med. 2005, 39, 196-204. [CrossRef] [PubMed]

4. Werner, C.; Engelhard, K. Pathophysiology of Traumatic Brain Injury. BJA Br. J. Anaesth. 2007, 99, 4-9. [CrossRef] [PubMed]

5. Neri, M.; Frati, A.; Turillazzi, E.; Cantatore, S.; Cipolloni, L.; Paolo, M.D.; Frati, P.; Russa, R.L.; Maiese, A.; Scopetti, M.; et al. Immunohistochemical Evaluation of Aquaporin-4 and Its Correlation with CD68, IBA-1, HIF-1 $\alpha$, GFAP, and CD15 Expressions in Fatal Traumatic Brain Injury. Int. J. Mol. Sci. 2018, 19, 3544. [CrossRef] [PubMed]

6. Hibbard, M.R.; Uysal, S.; Kepler, K.; Bogdany, J.; Silver, J. Axis I Psychopathology in Individuals with Traumatic Brain Injury. J. Head Trauma Rehabil. 1998, 13, 24-39. [CrossRef] [PubMed]

7. Tulsky, D.S.; Kisala, P.A.; Victorson, D.; Carlozzi, N.; Bushnik, T.; Sherer, M.; Choi, S.W.; Heinemann, A.W.; Chiaravalloti, N.; Sander, A.M.; et al. TBI-QOL: Development and Calibration of Item Banks to Measure Patient Reported Outcomes Following Traumatic Brain Injury. J. Head Trauma Rehabil. 2016, 31, 40-51. [CrossRef] [PubMed]

8. Vaishnavi, S.; Rao, V.; Fann, J.R. Neuropsychiatric Problems after Traumatic Brain Injury: Unraveling the Silent Epidemic. Psychosomatics 2009, 50, 198-205. [CrossRef]

9. Dewan, M.C.; Rattani, A.; Gupta, S.; Baticulon, R.E.; Hung, Y.-C.; Punchak, M.; Agrawal, A.; Adeleye, A.O.; Shrime, M.G.; Rubiano, A.M.; et al. Estimating the Global Incidence of Traumatic Brain Injury. J. Neurosurg. 2018, 130, 1080-1097. [CrossRef]

10. Kreutzer, J.S.; Seel, R.T.; Gourley, E. The Prevalence and Symptom Rates of Depression after Traumatic Brain Injury: A Comprehensive Examination. Brain Inj. 2001, 15, 563-576. [CrossRef]

11. Hyder, A.A.; Wunderlich, C.A.; Puvanachandra, P.; Gururaj, G.; Kobusingye, O.C. The Impact of Traumatic Brain Injuries: A Global Perspective. NeuroRehabilitation 2007, 22, 341-353. [CrossRef] [PubMed]

12. Puvanachandra, P.; Hyder, A.A. Traumatic Brain Injury in Latin America and the Caribbean: A Call for Research. Salud Publica Mex. 2008, 50 (Suppl. 1), 3-5. [CrossRef] [PubMed]

13. Julio, C.C.M.C.; Torres, N.C.G.; Lozano, J.C.; Zúñiga, C.R. Aspectos clínicos y epidemiológicos del trauma cráneo encefálico en México. Vigil. Epidemiol. 2008, 26,1-4.

14. Alvis-Miranda, H.; Navas, C.; Villa-Delgado, R.; Rubiano Escobar, A.; Alcalá-Cerra, G.; Moscote-Salazar, L. Trends in Management of Traumatic Brain Injury by Emergency Physicians in Colombia. Panam. J. Trauma Crit. Care Emerg. Surg. 2013, 2, 134-138. [CrossRef]

15. Pradilla, A.G.; Vesga, A.B.E.; León-Sarmiento, F.E.; GENECO. [National neuroepidemiological study in Colombia (EPINEURO)]. Rev. Panam. Salud Publica 2003, 14, 104-111. [CrossRef] [PubMed]

16. MRC CRASH Trial Collaborators. Perel, P.; Arango, M.; Clayton, T.; Edwards, P.; Komolafe, E.; Poccock, S.; Roberts, I.; Shakur, H.; Steyerberg, E.; Yutthakasemsunt, S.; et al. Predicting Outcome after Traumatic Brain Injury: Practical Prognostic Models Based on Large Cohort of International Patients. BMJ 2008, 336, 425-429. [CrossRef]

17. Iaccarino, C.; Carretta, A.; Nicolosi, F.; Morselli, C. Epidemiology of Severe Traumatic Brain Injury. J. Neurosurg. Sci. 2018, 62, 535-541. [CrossRef]

18. Gosselin, R.A.; Spiegel, D.A.; Coughlin, R.; Zirkle, L.G. Injuries: The Neglected Burden in Developing Countries. Bull. World Health Organ. 2009, 87, 246-246a. [CrossRef]

19. Bonow, R.H.; Barber, J.; Temkin, N.R.; Videtta, W.; Rondina, C.; Petroni, G.; Lujan, S.; Alanis, V.; La Fuente, G.; Lavadenz, A. The Outcome of Severe Traumatic Brain Injury in Latin America. World Neurosurg. 2018, 111, e82-e90. [CrossRef]

20. Arango-Lasprilla, J.C.; Nicholls, E.; Villaseñor Cabrera, T.; Drew, A.; Jimenez-Maldonado, M.; Martinez-Cortes, M.L. HealthRelated Quality of Life in Caregivers of Individuals with Traumatic Brain Injury from Guadalajara, Mexico. J. Rehabil. Med. 2011, 43, 983-986. [CrossRef]

21. Finnanger, T.G.; Skandsen, T.; Andersson, S.; Lydersen, S.; Vik, A.; Indredavik, M. Differentiated Patterns of Cognitive Impairment 12 Months after Severe and Moderate Traumatic Brain Injury. Brain Inj. 2013, 27, 1606-1616. [CrossRef] [PubMed]

22. Seagly, K.S.; O'Neil, R.L.; Hanks, R.A. Pre-Injury Psychosocial and Demographic Predictors of Long-Term Functional Outcomes Post-TBI. Brain Inj. 2018, 32, 78-83. [CrossRef] [PubMed]

23. Franulic, A.; Horta, E.; Maturana, R.; Scherpenisse, J.; Carbonell, C. Organic Personality Disorder after Traumatic Brain Injury: Cognitive, Anatomic and Psychosocial Factors. A 6 Month Follow-Up. Brain Inj. 2000, 14, 431-439. [CrossRef] [PubMed]

24. Marsh, N.V.; Knight, R.G. Behavioral Assessment of Social Competence Following Severe Head Injury. J. Clin. Exp. Neuropsychol. 1991, 13, 729-740. [CrossRef]

25. Struchen, M.A.; Clark, A.N.; Sander, A.M.; Mills, M.R.; Evans, G.; Kurtz, D. Relation of Executive Functioning and Social Communication Measures to Functional Outcomes Following Traumatic Brain Injury. NeuroRehabilitation 2008, 23, 185-198. [CrossRef] 
26. Dikmen, S.S.; Machamer, J.E.; Powell, J.M.; Temkin, N.R. Outcome 3 to 5 Years after Moderate to Severe Traumatic Brain Injury. Arch. Phys. Med. Rehabil. 2003, 84, 1449-1457. [CrossRef]

27. Bullinger, M.; Azouvi, P.; Brooks, N.; Basso, A.; Christensen, A.-L.; Gobiet, W.; Greenwood, R.; Hütter, B.; Jennett, B.; Maas, A.; et al. Quality of Life in Patients with Traumatic Brain Injury-Basic Issues, Assessment and Recommendations. Restor. Neurol. Neurosci. 2002, 20, 111-124.

28. Spilker, B. Quality of Life and Pharmacoeconomics in Clinical Trials; Lippincott-Raven: Philadelphia, PA, USA, 1996.

29. Hu, X.-B.; Feng, Z.; Fan, Y.-C.; Xiong, Z.-Y.; Huang, Q.-W. Health-Related Quality-of-Life after Traumatic Brain Injury: A 2-Year Follow-up Study in Wuhan, China. Brain Inj. 2012, 26, 183-187. [CrossRef]

30. Andelic, N.; Sigurdardottir, S.; Schanke, A.-K.; Sandvik, L.; Sveen, U.; Roe, C. Disability, Physical Health and Mental Health 1 Year after Traumatic Brain Injury. Disabil. Rehabil. 2010, 32, 1122-1131. [CrossRef]

31. Polinder, S.; Haagsma, J.A.; van Klaveren, D.; Steyerberg, E.W.; van Beeck, E.F. Health-Related Quality of Life after TBI: A Systematic Review of Study Design, Instruments, Measurement Properties, and Outcome. Popul. Health Metr. $2015,13,4$. [CrossRef]

32. Arango-Lasprilla, J.C.; Krch, D.; Drew, A.; De Los Reyes Aragon, C.J.; Stevens, L.F. Health-Related Quality of Life of Individuals with Traumatic Brain Injury in Barranquilla, Colombia. Brain Inj. 2012, 26, 825-833. [CrossRef] [PubMed]

33. Milders, M.; Fuchs, S.; Crawford, J.R. Neuropsychological Impairments and Changes in Emotional and Social Behaviour Following Severe Traumatic Brain Injury. J. Clin. Exp. Neuropsychol. 2003, 25, 157-172. [CrossRef] [PubMed]

34. Harris, J.K.; Godfrey, H.P.; Partridge, F.M.; Knight, R.G. Caregiver Depression Following Traumatic Brain Injury (TBI): A Consequence of Adverse Effects on Family Members? Brain Inj. 2001, 15, 223-238. [CrossRef] [PubMed]

35. Balducci, C.; Mnich, E.; McKee, K.J.; Lamura, G.; Beckmann, A.; Krevers, B.; Wojszel, Z.B.; Nolan, M.; Prouskas, C.; Bien, B.; et al. Negative Impact and Positive Value in Caregiving: Validation of the COPE Index in a Six-Country Sample of Carers. Gerontologist 2008, 48, 276-286. [CrossRef] [PubMed]

36. Pearlin, L.I.; Schieman, S.; Fazio, E.M.; Meersman, S.C. Stress, Health, and the Life Course: Some Conceptual Perspectives. J. Health Soc. Behav. 2005, 46, 205-219. [CrossRef] [PubMed]

37. Pinquart, M.; Sörensen, S. Associations of Stressors and Uplifts of Caregiving with Caregiver Burden and Depressive Mood: A Meta-Analysis. J. Gerontol. B Psychol. Sci. Soc. Sci. 2003, 58, P112-P128. [CrossRef]

38. Schulz, R.; Beach, S.R. Caregiving as a Risk Factor for Mortality: The Caregiver Health Effects Study. JAMA 1999, 282, $2215-2219$. [CrossRef]

39. Griffin, J.M.; Lee, M.K.; Bangerter, L.R.; Van Houtven, C.H.; Friedemann-Sánchez, G.; Phelan, S.M.; Carlson, K.F.; Meis, L.A. Burden and Mental Health among Caregivers of Veterans with Traumatic Brain Injury/Polytrauma. Am. J. Orthopsychiatry 2017, 87, 139-148. [CrossRef]

40. Perrin, P.B.; Stevens, L.F.; Sutter, M.; Hubbard, R.; Díaz Sosa, D.M.; Espinosa Jove, I.G.; Arango-Lasprilla, J.C. Exploring the Connections between Traumatic Brain Injury Caregiver Mental Health and Family Dynamics in Mexico City, Mexico. PM R 2013, 5, 839-849. [CrossRef]

41. Arango-Lasprilla, J.C.; Quijano, M.C.; Aponte, M.; Cuervo, M.T.; Nicholls, E.; Rogers, H.L.; Kreutzer, J. Family Needs in Caregivers of Individuals with Traumatic Brain Injury from Colombia, South America. Brain Inj. 2010, 24, 1017-1026. [CrossRef]

42. Doyle, S.T.; Perrin, P.B.; Sosa, D.M.D.; Jove, I.G.E.; Lee, G.K.; Arango-Lasprilla, J.C. Connecting Family Needs and TBI Caregiver Mental Health in Mexico City, Mexico. Brain Inj. 2013, 27, 1441-1449. [CrossRef] [PubMed]

43. Stevens, L.F.; Arango-Lasprilla, J.C.; Deng, X.; Schaaf, K.W.; De los Reyes, A.C.J.; Quijano, M.C.; Kreutzer, J. Factors Associated with Depression and Burden in Spanish Speaking Caregivers of Individuals with Traumatic Brain Injury. NeuroRehabilitation 2012, 31, 443-452. [CrossRef] [PubMed]

44. Marsh, N.V.; Kersel, D.A.; Havill, J.A.; Sleigh, J.W. Caregiver Burden during the Year Following Severe Traumatic Brain Injury. J. Clin. Exp. Neuropsychol. 2002, 24, 434-447. [CrossRef] [PubMed]

45. Kreutzer, J.S.; Rapport, L.J.; Marwitz, J.H.; Harrison-Felix, C.; Hart, T.; Glenn, M.; Hammond, F. Caregivers' Well-Being after Traumatic Brain Injury: A Multicenter Prospective Investigation. Arch. Phys. Med. Rehabil. 2009, 90, 939-946. [CrossRef] [PubMed]

46. Ponsford, J.; Olver, J.; Ponsford, M.; Nelms, R. Long-Term Adjustment of Families Following Traumatic Brain Injury Where Comprehensive Rehabilitation Has Been Provided. Brain Inj. 2003, 17, 453-468. [CrossRef]

47. Turner, B.; Fleming, J.; Cornwell, P.; Worrall, L.; Ownsworth, T.; Haines, T.; Kendall, M.; Chenoweth, L. A Qualitative Study of the Transition from Hospital to Home for Individuals with Acquired Brain Injury and Their Family Caregivers. Brain Inj. 2007, 21, 1119-1130. [CrossRef]

48. Linn, R.T.; Allen, K.; Willer, B.S. Affective Symptoms in the Chronic Stage of Traumatic Brain Injury: A Study of Married Couples. Brain Inj. 1994, 8, 135-147. [CrossRef]

49. Findler, M.; Cantor, J.; Haddad, L.; Gordon, W.; Ashman, T. The Reliability and Validity of the SF-36 Health Survey Questionnaire for Use with Individuals with Traumatic Brain Injury. Brain Inj. 2001, 15, 715-723. [CrossRef]

50. Guilfoyle, M.R.; Seeley, H.M.; Corteen, E.; Harkin, C.; Richards, H.; Menon, D.K.; Hutchinson, P.J. Assessing Quality of Life after Traumatic Brain Injury: Examination of the Short Form 36 Health Survey. J. Neurotrauma 2010, 27, 2173-2181. [CrossRef]

51. Alonso, J.; Prieto, L.; Antó, J.M. [The Spanish version of the SF-36 Health Survey (the SF-36 health questionnaire): An instrument for measuring clinical results]. Med. Clin. (Barcelona) 1995, 104, 771-776. 
52. Kroenke, K.; Spitzer, R.L.; Williams, J.B. The PHQ-9: Validity of a Brief Depression Severity Measure. J. Gen. Intern. Med. 2001, 16, 606-613. [CrossRef] [PubMed]

53. Kroenke, K.; Spitzer, R. The PHQ-9: A New Depression Diagnostic and Severity Measure. Psychiatr. Ann. 2002, 32, 509-521. [CrossRef]

54. Diez-Quevedo, C.; Rangil, T.; Sanchez-Planell, L.; Kroenke, K.; Spitzer, R.L. Validation and Utility of the Patient Health Questionnaire in Diagnosing Mental Disorders in 1003 General Hospital Spanish Inpatients. Psychosom. Med. 2001, 63, 679-686. [CrossRef] [PubMed]

55. Donlan, W.; Lee, J. Screening for Depression among Indigenous Mexican Migrant Farmworkers Using the Patient Health Questionnaire-9. Psychol. Rep. 2010, 106, 419-432. [CrossRef] [PubMed]

56. Perrin, P.B.; Stevens, L.F.; Villaseñor Cabrera, T.; Jimenez-Maldonado, M.; Martinez-Cortes, M.L.; Arango-Lasprilla, J.C. Just How Bad Is It? Comparison of the Mental Health of Mexican Traumatic Brain Injury Caregivers to Age-Matched Healthy Controls. NeuroRehabilitation 2013, 32, 679-686. [CrossRef] [PubMed]

57. Beetar, J.T.; Guilmette, T.J.; Sparadeo, F.R. Sleep and Pain Complaints in Symptomatic Traumatic Brain Injury and Neurologic Populations. Arch. Phys. Med. Rehabil. 1996, 77, 1298-1302. [CrossRef]

58. Hoffman, J.M.; Pagulayan, K.F.; Zawaideh, N.; Dikmen, S.; Temkin, N.; Bell, K.R. Understanding Pain after Traumatic Brain Injury: Impact on Community Participation. Am. J. Phys. Med. Rehabil. 2007, 86, 962-969. [CrossRef]

59. Uomoto, J.M.; Esselman, P.C. Traumatic Brain Injury and Chronic Pain: Differential Types and Rates by Head Injury Severity. Arch. Phys. Med. Rehabil. 1993, 74, 61-64.

60. Sullivan-Singh, S.; Sawyer, K.; Ehde, D.; Bell, K.; Temkin, N.; Dikmen, S.; Williams, R.; Hoffman, J. Comorbidity of Pain and Depression Among Persons with Traumatic Brain Injury. Arch. Phys. Med. Rehabil. 2014, 95. [CrossRef]

61. Lahz, S.; Bryant, R.A. Incidence of Chronic Pain Following Traumatic Brain Injury. Arch. Phys. Med. Rehabil. 1996, 77, 889-891. [CrossRef]

62. Nampiaparampil, D.E. Prevalence of Chronic Pain after Traumatic Brain Injury: A Systematic Review. JAMA 2008, 300, 711-719. [CrossRef] [PubMed]

63. Perrin, P.B.; Norup, A.; Caracuel, A.; Bateman, A.; Tjørnlund, M.; Arango-Lasprilla, J.C. An Actor-Partner Interdependence Model of Acquired Brain Injury Patient Impairments and Caregiver Psychosocial Functioning: A Dyadic-Report, Multinational Study. J. Clin. Psychol. 2017, 73, 279-293. [CrossRef] [PubMed]

64. Kreutzer, J.S.; Gervasio, A.H.; Camplair, P.S. Patient Correlates of Caregivers' Distress and Family Functioning after Traumatic Brain Injury. Brain Inj. 1994, 8, 211-230. [CrossRef] [PubMed]

65. Flor, H.; Fydrich, T.; Turk, D.C. Efficacy of Multidisciplinary Pain Treatment Centers: A Meta-Analytic Review. Pain 1992, 49, 221-230. [CrossRef]

66. Lemstra, M.; Stewart, B.; Olszynski, W.P. Effectiveness of Multidisciplinary Intervention in the Treatment of Migraine: A Randomized Clinical Trial. Headache 2002, 42, 845-854. [CrossRef]

67. McCracken, L.M.; Turk, D.C. Behavioral and Cognitive-Behavioral Treatment for Chronic Pain: Outcome, Predictors of Outcome, and Treatment Process. Spine (Phila Pa 1976) 2002, 27, 2564-2573. [CrossRef]

68. Branca, B.; Lake, A.E. Psychological and Neuropsychological Integration in Multidisciplinary Pain Management after TBI. J. Head Trauma Rehabil. 2004, 19, 40-57. [CrossRef]

69. Niemann, Y.F. Stereotypes of Chicanas and Chicanos: Impact on Family Functioning, Individual Expectations, Goals, and Behavior. In The Handbook of Chicana/o Psychology and Mental Health; Lawrence Erlbaum Associates Publishers: Mahwah, NJ, USA, 2004; pp. 61-82.

70. Santiago-Rivera, A.L.; Arredondo, P.; Gallardo-Cooper, M. Counseling Latinos and La Familia: A Practical Guide; Sage Publications Inc.: Thousand Oaks, CA, USA, 2002.

71. McCubbin, M.A.; McCubbin, H.I. Theoretical Orientations to Family Stress and Coping. In Treating Stress in Families, Brunner/Mazel Psychosocial Stress Series, No. 13; Brunner/Mazel: Philadelphia, PA, USA, 1989; pp. 3-43.

72. Lehan, T.; Arango-Lasprilla, J.C.; de los Reyes, C.J.; Quijano, M.C. The Ties That Bind: The Relationship between Caregiver Burden and the Neuropsychological Functioning of TBI Survivors. NeuroRehabilitation 2012, 30, 87-95. [CrossRef]

73. Albert, S.M.; Im, A.; Brenner, L.; Smith, M.; Waxman, R. Effect of a Social Work Liaison Program on Family Caregivers to People with Brain Injury. J. Head Trauma Rehabil. 2002, 17, 175-189. [CrossRef]

74. Brown, R.; Pain, K.; Berwald, C.; Hirschi, P.; Delehanty, R.; Miller, H. Distance Education and Caregiver Support Groups: Comparison of Traditional and Telephone Groups. J. Head Trauma Rehabil. 1999, 14, 257-268. [CrossRef]

75. Carnevale, G.J.; Anselmi, V.; Busichio, K.; Millis, S.R. Changes in Ratings of Caregiver Burden Following a Community-Based Behavior Management Program for Persons with Traumatic Brain Injury. J. Head Trauma Rehabil. 2002, 17, 83-95. [CrossRef] [PubMed]

76. Rivera, P.A.; Elliott, T.R.; Berry, J.W.; Grant, J.S. Problem-Solving Training for Family Caregivers of Persons with Traumatic Brain Injuries: A Randomized Controlled Trial. Arch. Phys. Med. Rehabil. 2008, 89, 931-941. [CrossRef] [PubMed] 